\title{
Esophagectasis Related to Rivastigmine
}

\author{
Osamu Sasaki, Kazunori Sugimura, Masahiro Shinoda and Masaharu Shinkai
}

Key words: esophagectasis, rivastigmine

(Intern Med 58: 1527, 2019)

(DOI: 10.2169/internalmedicine.2137-18)

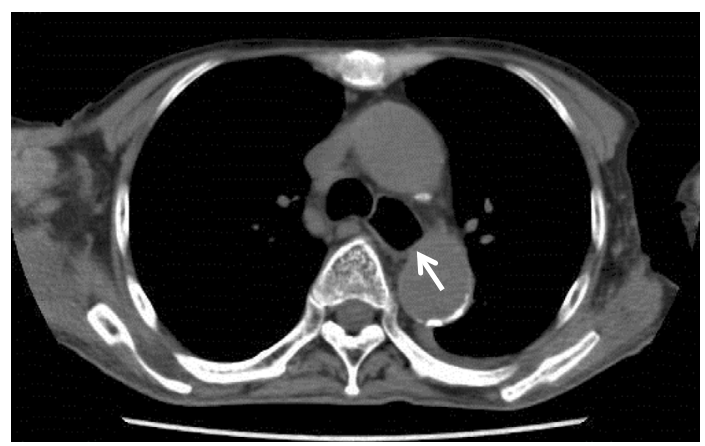

Picture 1.

An 86-year-old man with a history of Alzheimer's dementia was admitted for appetite loss, nausea and weight loss. He had been receiving the acetylcholinesterase inhibitor (AChEI) rivastigmine at a dose of $18 \mathrm{mg} /$ day, mirabegron $25 \mathrm{mg} /$ day, suvorexant $15 \mathrm{mg} /$ day, quetiapine fumarate 25 $\mathrm{mg} /$ day, esomeprazole magnesium hydrate $20 \mathrm{mg} / \mathrm{day}$, tulobuterol $1 \mathrm{mg} /$ day, isosorbide mononitrate $40 \mathrm{mg} /$ day, clopidogrel sulfate $50 \mathrm{mg} /$ day, atenolol $12.5 \mathrm{mg} /$ day, and memantine hydrochloride $5 \mathrm{mg} /$ day. Computed tomography (CT) of the chest revealed remarkable esophagectasis (Picture 1, maximum diameter: $27.1 \mathrm{~mm}$ ). Upper gastrointestinal endoscopy revealed no significant findings, and esophageal dilatation and achalasia were not detected. Suspecting the adverse effects of rivastigmine, we reduced the dose gradually to $4.5 \mathrm{mg} /$ day, and his appetite fully recovered. All other drugs aside from rivastigmine were unchanged. CT revealed a significant improvement in the dilatation of the esophagus (Picture 2, maximum diameter: $18.1 \mathrm{~mm}$ ). One of the adverse effects of rivastigmine is digestive symptoms, such as appetite loss, nausea and-rarely-rupture of the

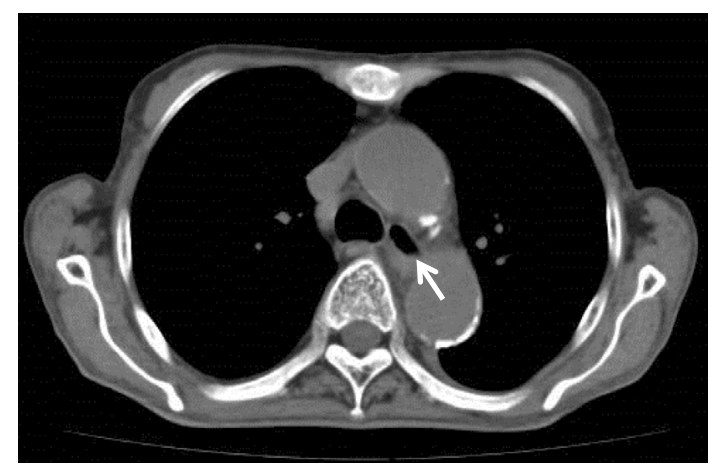

Picture 2.

esophagus (1). After reducing the dose of rivastigmine, CT showed remarkable changes consistent with symptom resolution. The present case shows that rivastigmine can induce esophagectasis with appetite loss as an adverse effect. Clinicians should consider performing CT examinations for dementia patients suffering from digestive symptoms who are using AChEIs.

The authors state that they have no Conflict of Interest (COI).

\section{Reference}

1. Babic T, Banfic L, Papa J, Barisic N, Jelincic Z, Zurak N. Spontaneous rupture of oesophagus (Boerhaave's syndrome) related to rivastigmine. Age Ageing 29: 370-371, 2000

The Internal Medicine is an Open Access journal distributed under the Creative Commons Attribution-NonCommercial-NoDerivatives 4.0 International License. To view the details of this license, please visit (https://creativecommons.org/licenses/ by-nc-nd/4.0/). 